\title{
TENSIONES SOCIALES EN EL VALLE DEL Ebro \\ DURANTE LA CRISIS DEL SIGLO XVII: \\ La Destrucción del yacimiento de “TudejÉN” (Navarra)
}

"Social pressures in the middle valley of the Ebro during the crisis of the 17th century: the demolition of the archeological site of Tudején (Navarre)"

\section{Francisco José Alfaro Pérez ${ }^{1}$}

Recibido: 15-04-2020

Aceptado: 20-05-2020

\section{Resumen}

Entre otras consecuencias, la crisis del siglo XVII provocó un notable incremento de la tensión social en determinados puntos del valle medio del Ebro. Uno de esos focos fue el señorío eclesiástico de Fitero, cuya villa se vería obligada a destrozar un yacimiento arqueológico para sembrarlo de trigo.

Palabras Claves: subsistencia, conflicto, agricultura, yacimiento, expolio.

\begin{abstract}
Among other consequences, the17th century crisis produced a remarkable increase in the social pressures in certain points of the middle valley of the Ebro river. One of these sources was the ecclesiastical lordship of Fitero, which town was compelled to demolish an archeological site in order to grow wheat.
\end{abstract}

Keywords: subsistence, conflict, farming, archeological site, plunder. 


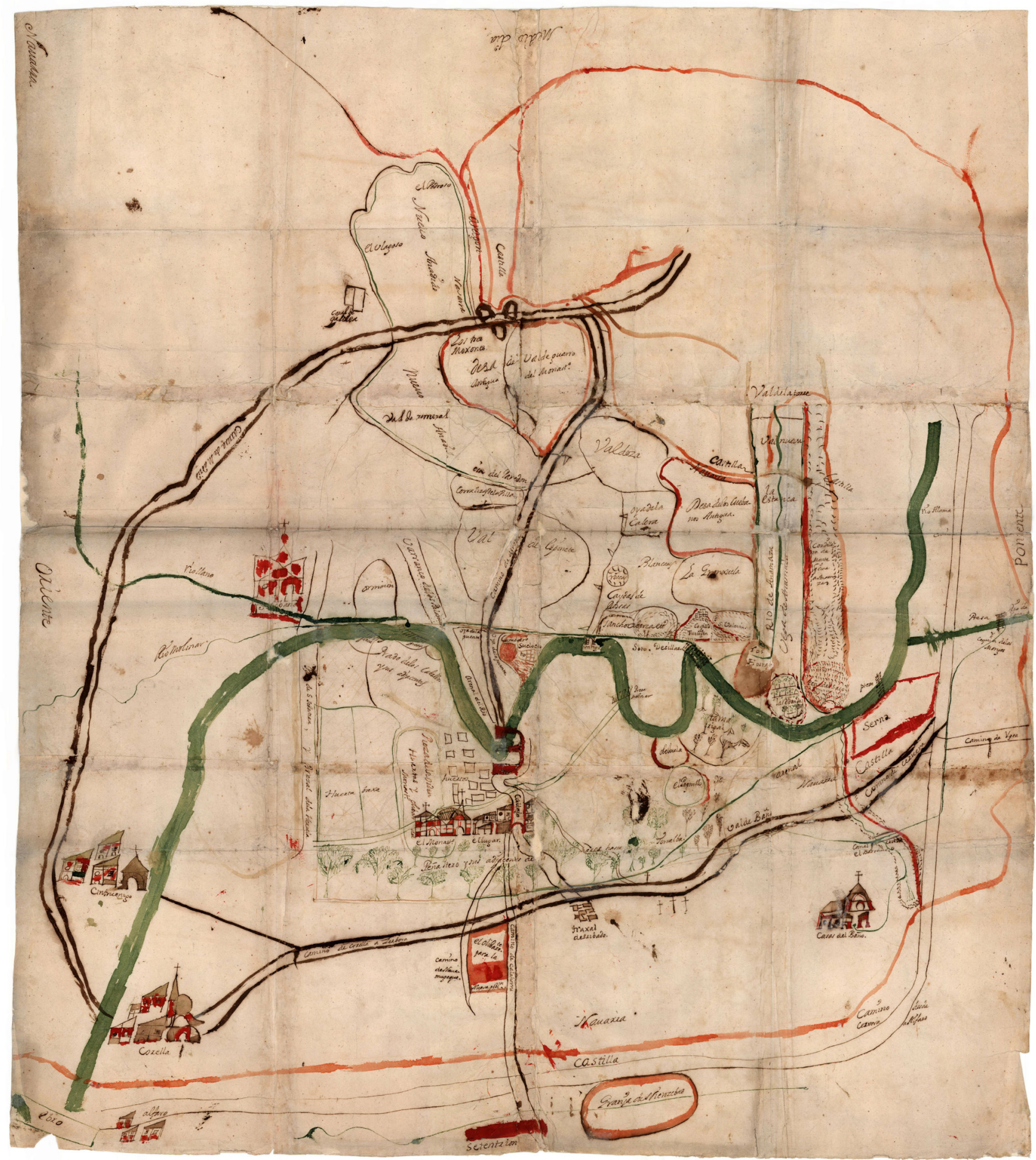

Fig. I: Plano del término de Tudején, monasterio, villa y balneario de Fitero (Navarra) elaborado en 1655 con motivo del Apeo de Feloaga. Fuente: Archivo General de Navarra.

Como en otros muchos lugares, el siglo XVII también fue una centuria complicada para las gentes del valle del Ebro (Fig. 1). ${ }^{2}$ Las dificultades de las décadas previas fueron superadas con un saldo demográfico positivo, lo cual supuso un incremento poblacional que se transformaría en mayor presión cuando, algunos años más tarde, la tendencia general (económica y demográfica) se invirtiera

2 Archivo General de Navarra, ES/NA/AGN/13-2/FIG_CARTOGRAFÍA, N.52. Recogido y tratado en ALFARO PÉREZ, F.J., Mapa del monasterio y la villa de Fitero con todo su término e inmediaciones. En: FERNÁNDEZ GRACIA, R., Fitero: el legado de un monasterio, Pamplona: Gobierno de Navarra, 2007, pp. 178-179. 
apuntando en unas ocasiones hacia el estancamiento, en otras a la recesión ${ }^{3}$. Factores climáticos ${ }^{4}$ y políticos ${ }^{5}$ fueron en buena medida sus causantes, aunque hubo otros ${ }^{6}$. La coyuntura creada derivó en unos intentos de reajuste, en ocasiones frustrados que, a su vez, hicieron aflorar tensiones sociales tanto en lugares de realengo como, y sobre todo, en señoríos laicos o religiosos como el que aquí se trata$^{7}$. La lucha por la supervivencia — la necesidad — y la atemporal ambición de las personas supuso que, puntualmente, algunos yacimientos arqueológicos fueran arrasados con el fin de incrementar las tierras de cultivo, la producción. Actos que no siempre han quedado documentados y que, sin duda, contribuyeron a destruir fuentes materiales y aun a la propia memoria colectiva ${ }^{8}$ a cambio de un puñado de granos. Actitudes que, por cierto, se han mantenido en otros muchos momentos posteriores - algunos bien recientes - en coyunturas radicalmente opuestas y, en teoría, ante la observancia de unas autoridades celosas, una cultura generalizada y una sensibilidad por parte de propietarios de terrenos dadas por supuesto, pero no.

Esto es lo que ha venido ocurriendo con la villa desierta de Tudején, situada en el encuentro fronterizo de las antiguas coronas de Castilla, Aragón y Navarra, en un lugar estratégico entre el somontano ibérico y el valle del Ebro. Célebre por el Tratado que lleva su nombre acordado por Alfonso VII de Castilla y Ramón Berenguer IV de Aragón, en 1151, en un intento por repartirse el reino de Navarra a la muerte de García Ramírez. Donado junto a su castillo al monasterio de Santa María la Real en su etapa fundacional, pasaría definitivamente a manos navarras en el último cuarto del siglo XIV. Por lo que se refiere a su destrucción, que es lo que en estas líneas interesa, es conocido cómo la villa debió quedar deshabitada pronto, poco después del pacto entre los monarcas castellano-aragoneses;

\footnotetext{
3 Ambos aspectos son descritos y analizados con nitidez en REHER SULLIVAN, D. S., Castilla y la crisis del siglo XVII: contextos demográficos para un ajuste de larga duración. En: E. MARTÍNEZ RUIZ, (coord.), Felipe II y las ciudades de la monarquía, Madrid:2000, vol. 2, pp. 347-374; y SALAS AUSENS, J. A., Las haciendas concejiles aragonesas en los siglos XVI y XVII, de la euforia a la quiebra. En: J. A. SALAS AUSÉNS, A. ALBEROLA, E. GIMÉNEZ, P. MOLA, y J. I. FORTEA, Poder político e instituciones en la España moderna, Alicante, 1992, pp. 9-66.
}

4 Sobre su afección social en el valle del Ebro véase CUADRAT, J. M., ALFARO PÉREZ, F. J., TEJEDOR, E., SERRANO-NOTIVOLI, R., BARRIENDOS, M. y SAZ, M. Á., La sequía de mediados del siglo XVII en el valle del Ebro. Características climáticas e impacto social del evento. En: Ma HERNÁNDEZ, J. OLCINA y J. F. VERA, J. F., Paisaje, Cultura territorial y vivencia de la Geografia, Alicante: Universidad de Alicante, 2016, pp. 883-893. Con carácter más amplio pueden consultarse, entre otros, ALBEROLA ROMÁ, A., Los cambios climáticos. La Pequeña Edad del Hielo en España, Madrid: Cátedra, 2014; o FAGAN, B., La Pequeña Edad del Hielo. Cómo el clima afectó a la historia de Europa (1300-1850), Barcelona: Gedisa, 2008.

5 Entre la ingente bibliografía existente sobre la cuestión, para una visión general del caso hispánico pueden verse, entre otros, los trabajos recogidos por PARKER, G. (coord.). La crisis de la Monarquía de Felipe IV, Barcelona, Crítica 2006.

6 Entre estos otros destacan los episodios de sobremortalidad causados por epidemias de distinta naturaleza. Véase PÉREZ MOREDA, V., Las crisis de mortalidad en la España interior (siglos XVI-XIX). Madrid: Siglo XXI, 1980.

7 Así puede observarse en CATALÁN MARTÍNEZ, E., El clero ante la crisis del siglo XVII. Conflictos y estrategias. Tiempos modernos. Revista electrónica. 2010, vol. 7, n² 20; o USUNÁRIZ GARAYOA, J. M., Nuevos señoríos, nuevos señores: Navarra y la venta de jurisdicciones durante la Edad Moderna. Cuadernos de Investigación Histórica. 1999, nº 17, pp. 7-36.

8 Por utilizar el término en el sentido que lo usó MENÉNDEZ PIDAL DE NAVASCUÉS, F., La destrucción de la memoria colectiva. Un ejemplo navarro. En: III Congreso General de Historia de Navarra, Pamplona 20-23 de septiembre de 1994, Área III. El mundo de las ideas. 1994, pp. 1-8. Como guía para comprobar la degeneración patrimonial de la villa de Fitero en los últimos años puede seguirse OLCOZ YANGUAS, S., El tesoro del patrimonio histórico de Fitero, Fitero, 2007.

9 Para más información, entre otros, véase GARCÍA SESMA, M., Poemario fiterano con notas históricas, anecdóticas y descriptivas de la villa, el monasterio y los balnearios de Fitero, Pamplona, 1989; del mismo: Investigaciones históricas sobre Fitero, Tudela, 1986, Vol I; e Investigaciones históricas sobre Fitero, Logroño, 1989; y OLCOZ YANGUAS, S., Fitero cisterciense, del Monasterio a la Villa (siglos XII-XV), Fitero:Tracasa, 2008; del mismo, Memorias del monasterio de Fitero, del padre Calatayud, Pamplona: Gobierno de Navarra, 2005. 
así como que los sucesivos intentos por repoblarla fueron todos ellos infructuosos. Más allá del deterioro motivado por el paso del tiempo y el abandono, y por ser su entorno campo de batalla y pillaje, su castillo fue mandado desmochar y semiderruir tras la Conquista de Navarra y la tentativa de 1521 en la que las gentes de la zona se alzaron en apoyo al general Asparros ${ }^{10}$. Desde entonces hasta los últimos años del siglo XX el yacimiento no habría experimentado daños de consideración, o esto es lo que se pensaba hasta la aparición del documento que aquí presentamos donde se muestra, desafortunadamente, una evolución bastante más accidentada.

A partir de los años ochenta del siglo XV la contigua villa de Fitero, surgida aguas abajo al socaire de las murallas monacales - y a la que se consideró heredera de Tudején-, comenzó a crecer de un modo rápido gracias al flujo migratorio de algunas minorías expulsas de los reinos vecinos, de castellanos exiliados en sus guerras de bandos y por la estabilización de una frontera que dejó de ser belicosa más allá de puntuales conflictos concejiles. De forma paralela a su desarrollo surgió ex novo una grave tensión entre unos vasallos inconformistas y un señor jurisdiccional enrocado, o lo que es lo mismo: el choque de intereses entre las urgencias de la villa frente a los derechos medievales (legales) del viejo cenobio ${ }^{11}$. Desde mediados del siglo XVI los conflictos fueron continuos y muy costosos para ambas partes y, aunque aletargados o más comedidos desde fines del siglo XVII, no desaparecieron hasta una desamortización decimonónica que acabó con el primitivo dueño reemplazando a la villa un yugo feudal por otro caciquil.

Las ansias de libertad, o de apartar de los derechos consuetudinarios del monasterio en favor de un común que no los poseía pero que los precisaba, se plasmaron a través de diferentes grandes empresas acometidas por el concejo como fueron, entre otras, la compra de tierras en realengo - en Ormiñén y el Olivarete- , así como la pugna por hacerse con las jurisdicciones media y baja. Junto a éstas hubo otras acciones "menores" destinadas al incremento de gozos y aprovechamientos de los recursos materiales del entorno. Una de ellas, una más, tuvo lugar el 5 de enero de 1603, cuando villa y monasterio acordaron un convenio por el que se autorizaba a la primera a ampliar sus tierras de regadío. Según se explica en el mismo, las 700 robadas que la localidad disponía para sembrar trigo de "pan llevar" no eran suficientes para mantener a una población que había crecido hasta los 350 vecinos, motivo por el cual se veía obligada a gastar anualmente la cantidad de unos 6.000 ducados en la compra de dicho cereal ${ }^{12}$.

El pasaje que se detalla en el documento aquí aportado es redactado tan solo quince años más tarde. En él confluye la cruda lucha por la subsistencia con otro tipo de intenciones, ambiciones y sentimien-

10 Sobre la cuestión deben consultarse MEDRANO MARQUÉS, M. y DÍAZ SANZ, M. A., Ocupación romana bajomedieval de Tudején (Fitero). I Congreso General de Historia de Navarra, Pamplona: Príncipe de Viana, 1987, pp. 503-515; MEDRANO MARQUÉS, M., Los visigodos en el solar de Fitero (el castillo de Tudején), Fitero, 2002; y, del mismo, El asentamiento visigodo y musulmán de Tudején-Sanchoabarca. Salduie, 4, 2004, pp. 261-302 o, más recientemente, El castillo de Tudején y su entorno: últimas investigaciones. Salduie, 17, 2018, pp. 169-176.

11 Puede verse sobre la cuestión USUNÁRIZ GARAYOA, J. M., ¡Muera ese traidor, matadlo! Fitero y su régimen señorial en la Edad Moderna. En: I. ARELLANO AYUSO (coord.), Modelos de vida y cultura en la Navarra de la modernidad temprana, Madrid: Instituto de Estudios Auriseculares, 2016, pp. 319-363; o ALFARO PÉREZ, Fco. J., ¡Ni abad por vecino ni fraile maitino! Análisis transversal de un conflicto antiseñorial del siglo XVII. Studia Monastica. 2019, vol. 61, pp. 175-185.

12 Archivo Municipal de Corella, Legajo 19, Libro Lit. C, documento 6. Recogido por IDOATE, F., Catálogo documental de la ciudad de Corella, Pamplona: Institución Príncipe de Viana, 1964, doc. nº 405, p. 93. 
tos. Es difícil discernir hasta dónde llegan los extremos de unos y de otros por estar complejamente entrelazados. En el proceso, el concejo — o al menos sus dirigentes - cuestionó la localización y sus límites, la realidad jurídica, perdió. Así, a comienzos de los años veinte del siglo XVII entró y roturó parte de las construcciones del entorno de San Valentín - la villa desierta de Tudején según el monasterio - y lo quiso sembrar de trigo, creó balsas para el cáñamo y heleras ${ }^{13}$, al igual que el monasterio había hecho poco antes allí mismo - y en otros yacimientos situados en los montes de Cierzo o en otros términos del coto redondo-. ¿Tenía alguna razón la villa? Depende de los mojones alegados, en principio quizás no —o sí-, en cualquier caso, vivía al límite y sus gentes lo necesitaban tanto para su subsistencia como para culminar su empeño de emanciparse del monasterio y tener su propia jurisdicción ${ }^{14}$. A esta conclusión se llega con facilidad si tenemos en cuenta que apenas cinco años más tarde, en 1631, una terrible hambruna le causó mayor número de muertes que cualquier peste, enfermedad o guerra en otro momento del Antiguo Régimen.

\section{Evolución demográfica de la villa de Fitero (1624-1645) ${ }^{15}$}

El interés del documento aquí aportado tiene distintas vertientes. Desde un punto de vista histórico y económico es evidente; e incluso para la arqueología, no sólo por reconstruir los avatares de un yacimiento. Del mismo modo permite acotar algunas cronologías y conocer ciertos comportamientos sociales en un periodo extremadamente duro y convulso. Desde el otero de la Historia del Arte, entre otros detalles, se muestra sugestivo al menos por dos motivos que coinciden con sendas e incipientes líneas de estudio. La primera de ellas referida a la reutilización de los materiales —en este caso pé-

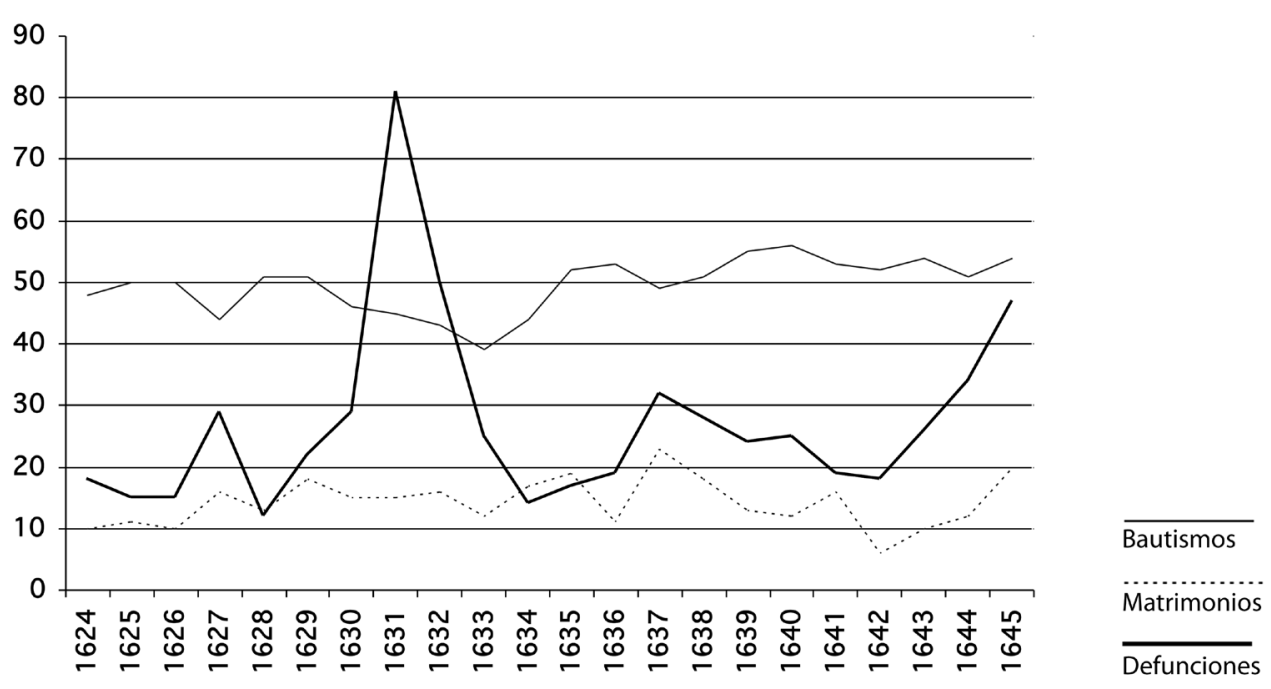

13 Sobre el funcionamiento de las heleras de Tudején y anexos véase OLCOZ YANGUAS, S., Eleras en Fitero. Fitero (Programa), 1982, pp. 44-45.

14 En ese mismo periodo la villa compró unas jurisdicciones que el monasterio, posteriormente, recompraría incrementando aún más la tensión.

15 Véase ALFARO PÉREZ, Fco. J., La Merindad de Tudela en la Edad Moderna. Demografía y sociedad, Tudela: ADEH, Institución Fernando el Católico y los MM. II. Aytos. de Fitero, Corella y Tudela, 2006. 
treos- de las construcciones antiguas para reedificar o construir otras más modernas ${ }^{16}$. Sería el caso de la helera que aún se conserva en Tudején (Fig. 2), pero también de otras (al menos diez más) que se hallan enterradas y rellenadas.

El segundo se refiere al propio expolio de los materiales del yacimiento. Podemos constatar cómo Juan Francés de Villalobos se llevó “(...) una Botija de las que avian sacado, la qual venia mostrando a todos los que encontrava

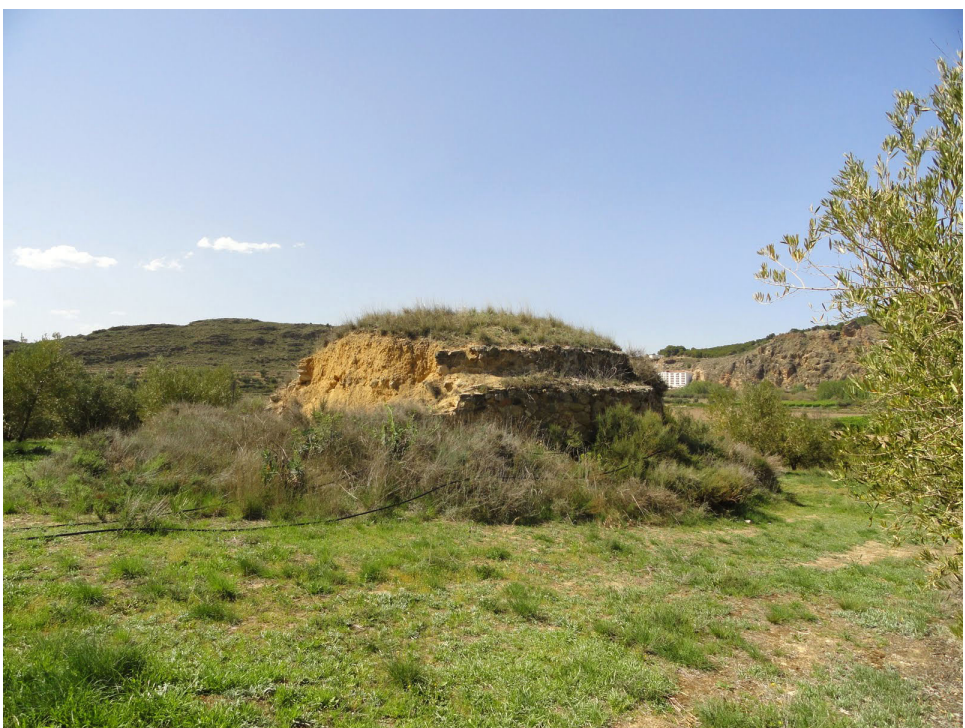

Fig. 2: Elera de Tudején (Navarra), siglo XVII. Fuente: Turismo de Fitero.

$y$ diciendoles la havia de guardar para Memoria", aunque con total certeza han sido muchísimos más los objetos retirados. ¿Dónde han ido a parar?, ¿qué es de ellos? Las más de las veces, los instrumentos "menos valiosos" debieron perderse o romperse, simplemente han desaparecido. Otros en cambio pudieron ir a manos de anticuarios y coleccionistas de la época ${ }^{17}$. De los que han sido recuperados más

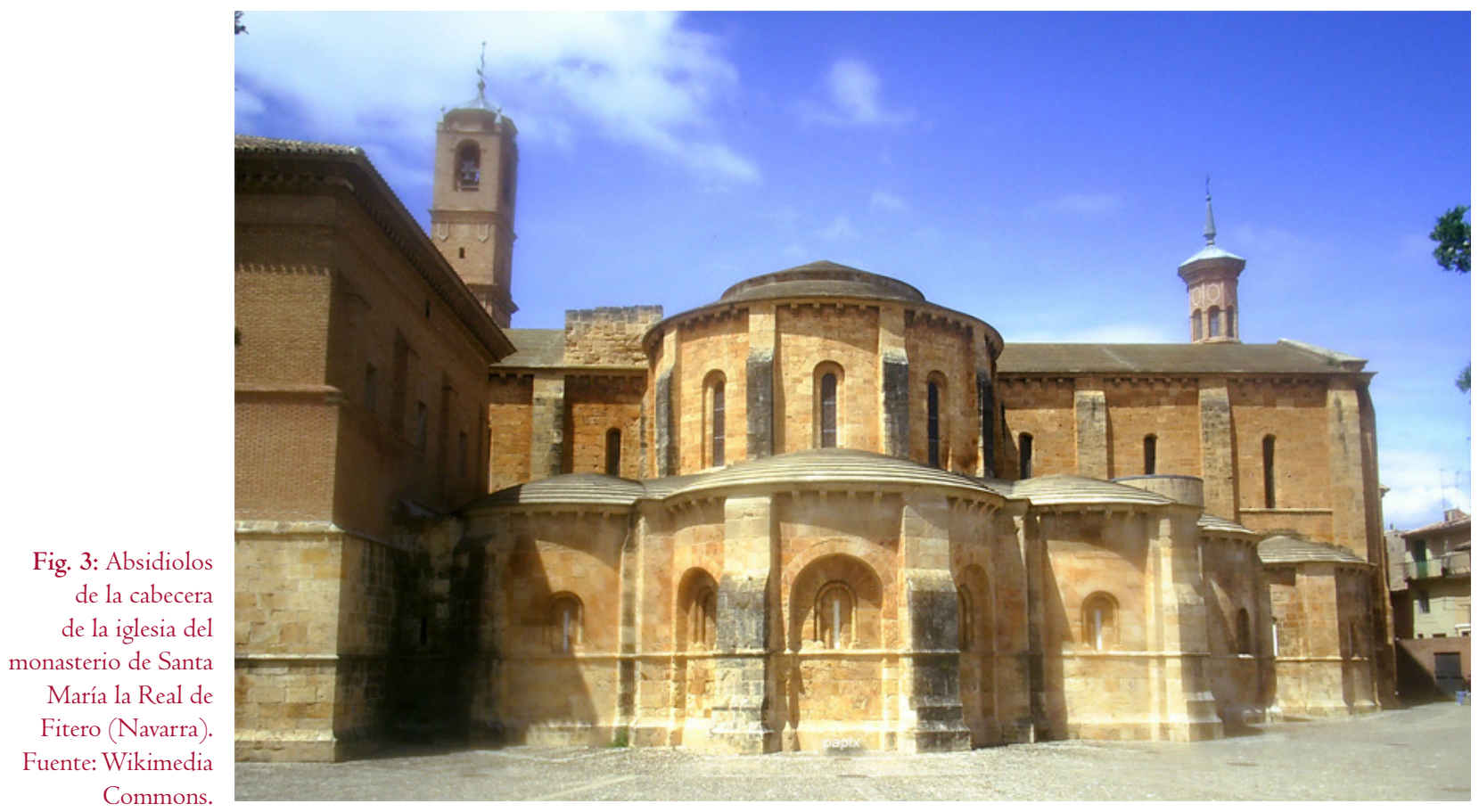

16 Sobre la cuestión, entre otros, puede verse para este periodo estudios como ARCINIEGA GARCÍA, L., Reutilización de materiales pétreos y uso de canteras en el abastecimiento de la arquitectura valenciana de época foral. En: Fca. ESPAÑOL BERTRÁN y J. VALERO MOLINA (Coords.). Les pedreres medievals a la Corona d'Aragó, Barcelona: Institut d'Estudis Catalans, 2017, pp. 149185; o, para momentos anteriores, WARD-PERKINS, B., Re-using the Architectural legacy of the Past, entre idéologie et pragmatisme. En: The idea and ideal of town between late Antiquity and Early Middle Age. Leiden,1999, pp. 225-244; MAYER, M., ÁLVAREZ, A- y RODÀ, I., Los materiales lapídeos reaprovechados en construcciones medievales en Cataluña: la ciudad de Barcelona y su entorno. En: Artistes, artisans et production artistique au Moyen Âge, Paris, 1987, pp. 529-558; o SÁNCHEZ PARDO, J. C., El reuso de materiales y estructuras antiguas en las iglesias altomedievales de Galicia, casos, problemas y motivaciones. Estudos Quaternário. 2015, 12, pp. 95-110, entre otros.

17 Sobre estos usos en el siglo XVII que nos ocupa puede verse MORÁN TURINA, M., La memoria de las piedras. Anticuarios, arqueólogos y coleccionistas de antigüedades en la España de los Austrias. Madrid, 2010. 
recientemente (monedas, hebillas, armas, etc.) algunos han sido puestos a disposición de las autoridades, siendo catalogados y entregados a los museos ${ }^{18}$. Otros en cambio han ido a parar al mercado negro.

Sirvan pues estas líneas para constatar el problema y para alertar que la mitad occidental de dicho yacimiento de San Valentín se mantiene relativamente virgen, desatendida e incluso empleada parcialmente de escombrera. Sería una lástima que lo que no se hizo por hambre se consintiera ahora por desidia o por ambiciones pobres y mal entendidas.

\section{Sobre las pozas de San Valentín y noticias históricas de la destrucción parcial del yacimiento arqueológico de Tudején (Navarra) ${ }^{19}$}

Miguel de Roxas, procurador del monasterio Real de Fitero (Fig. 3), con la protestacion ordinaria cuerello criminalmente contra Joan de Oñate, Martin Gomez, Pedro Pardo, Miguel de Ruperez, Joan Gomez de Cartagena, Alcalde, regidores de la dicha Villa de Fitero y de Joan Frances de Villalobos y contra los demas que se hallaren Culpados para lo que entiendo probar por los articulos siguientes:

Primeramente a los Veinte y seis de Febrero deste presente año 1624, Joan de Oñate, Martin Gomez, Pedro Pardo, Miguel de Ruperez y Joan Gomez de Cartagena, Alcalde y Regidores de la dicha Villa de Fitero y Joan Frances de Villa Lobos y otros muchos de Fitero, conbocados y llamados por mandado de los dichos Alcalde y Regidores por Joan Morales, nuncio de la dicha Villa, fueron al sitio y lugar donde antiguamente estuvo fundada la Villa de Trujen [Tudején] que es del dicho monasterio y deshicieron gran cantidad de cimientos y Ruinas que avia en el dicho sitio y lugar y de ellos sacaron un ingenio de piedra de sacar miel, unas tinajas, verças, ollas y botijas y otras cosas; y cuando se volvian a sus casas el dicho Villalobos trajo consigo una Botija de las que avian sacado, la qual venia mostrando a todos los que encontrava y diciendoles la havia de guardar para Memoria, y que ia tenia seguros la Villa de Fitero cuarenta robos de trigo de renta todos los años de alli delante de lo que nuevamente avianroçado y labrado por ella.

Ittem que los dichos Alcalde y Regimiento de la Villa de Fitero dieron orden y mandaron a Joan Morales, nuncio, conbocasse y llamasse a los Vecinos de la dicha Villa acudiesen con el dicho Alcalde y Regimiento al Sitio y Lugar donde estuvo fundada antiguamente la Villa de Trujen, advirtiendole que no avisase a algunas personas que lo nombraron por temor no diesen avisso al dicho monasterio de lo que pretendian hacer los quales acudieron cuales con açada o picas y otros instrumentos y otros con iuntas como diran los testigos.

Yttem que el dicho sitio y Lugar de la Villa de Trujen que pretenden sin ningun titulo apropiar para la Villa de Fitero y el Alcalde y Regimiento y demas Vecinos de ella a sido perpetuamente a la continua del dicho monasterio Real de Fitero por donaciones y mercedes de los Senores Reyes y esta incluso en medio de los terminos del dicho monasterio cue mando amojonar el señor Rey Don Alonso de Castilla

18 MEDRANO MARQUÉS, M., ref.10.

19 Sentencias. Traslado simple sobre las pozas de San Balentin y tambien contiene algunas noticias. Año 1624. Archivo Municipal de Fitero, Documentación Histórica, caja ${ }^{\circ} 443$, signat. antigua: doc. $n^{\circ} 33$, faxo 8. 
a los concejos de San Pedro de Yanguas, Cervera y Agreda el año 1216, destos 10, 20, 30, 40, 50, 100 y mas años continuos y demas tiempo y de tanto a esta parte que no ai memoria de ombres en contrario y lo an visto anssi los testigos por todo su tiempo y memoria que lo tienen demas de cuarenta años, lo oyeron deçir a sus mayores y mas ançianos, los quales deçian que lo avian visto y oido decir en sus tiempos a los suyos y que los unos ni los otros vieron ni oieron deçir lo contrario.

Y dello a sido y es publica Voz y Fama y común opinion en la dicha Villa de Fitero y su comarca y aun en todo este Reino y en el de Castilla y si en el dicho sitio y Lugar an tenido los Comuneros algún Goço en comunidad a sido tan solamente de las hiervas y aguas sin que jamas se ayaroçado ni labrado, y este goço a sido sin perjuicio de la propiedad que siempre a tenido y tiene el dicho monasterio en el como diran los testigos.

Yttem que en medio del dicho sitio y Lugar donde estuvo fundada la Villa de Trujen esta la iglesia de San Balentin que fue antiguamente la parroquia de la dicha Villa de Trujen de la qual y de sus diezmos y primicias hiçieron donacion el Obispo y Cavildo de Tarazona el año 1250 al monasterio Real de Fitero a donde asta de pocos años a esta parte todos los años venian en procession un dia de los de las Letanias la Villa de Çervera y su clerecia y dezian una missa y Rogativa y oidia todos los años van los monjes y la Villa de Fitero en procession a la dicha iglesia derruida de San Balentin el segundo dia de las Letanias y si aze buen tiempo hecha la Rogativa se dize missa y acabada se dize un responso cantado por todos los fieles difuntos que allí estan enterrados y tiene cuydado el que es Alcalde del Baño del dicho monasterio de prevenir y azer un altar y ara el dicho efecto y cojen la Limosna que se ofrece al ofertorio de la missa y si no se puede decir missa por la descomodidad del tiempo dizen solo la Rogativa y acabado el responso cantado por los fieles difuntos asistiendo a todo ello el Alcalde y Regimiento y Vecinos de la dicha Villa y se vuelben en procession al dicho monasterio a donde se dize la missa como diran los testigos.

Ittem que el dicho monasterio Real de Fitero esta en quieta y pacifica posesión de los 10, 20, 30, 40, 50 y 100 y mas años a la continua y de tanto tiempo que no ay memoria de ombres en contra en continuación de su derecho y posesión de llevar las Bezes que a subcedido passar ganados de los de Castilla por los terminos de la Villa de Trujen a llevado a solas y a cobrado el dicho monasterio dos Reses de ellos por el castillaje sin concurso de otro ningun y entero como es notorio y diran los testigos y constara por escritura.

Itten que los terminos que antiguamente llamaban de la Villa de Turujen son los mesmos que oi llaman de Fitero que de termino llamado Fitero a do esta fundado el dicho monasterio tomo el monasterio y todos sus terminos el apellido de Fitero, y en el dicho sitio y Lugar donde estuvo fundada la Villa de Trujen se veian los cimientos de las Casas y Ruinas de la iglesia parroquial de San Balentin y del Castillo que estaba algo apartado en un Cerro alto a dos tiros de Ballesta del dicho Lugar sitio como estanel de la Ciudad de Tudela y Villas de Cervera y Aguilar y otros muchos de otras diferentes Ciudades, Villas y Lugares y el sobre nombre tomo el Castillo d ela dicha Villa de Trujen como lo an tomado todos los demas de las Ciudades, Villas y Lugares de donde estan edificados como diran los testigos.

Yten que por las Sentencias de Vista y Revista del año 1623 se les mando a los contrarios derribassen y deshiciesen las eleras y poças y las cerrassen dejando el suelo como estaba antes que las abriessen y hiciesen y que de las poças no se pudiesen servir sino para efecto de benificar el cañamo en ellas y quando hizieron las dichas eleras deshiçieron algunos cimientos y tambien sacaron de ellos algunos trastos 
y cantidad de piedra, ni mas ni menos hiçieron quando las cerraron por mandado del Real Consejo las quales eleras estavan hechas en medio del sitio y Lugar de la Villa de Trujen y las poças a un lado del como todo es publico y notorio y lo diran los testigos.

Otrosi atento que las partes Contrarias proceden de el echo Suplico a V. Mgd. mande prober de inhibición penal en la forma ordinadira contra ellos para que no se entremetan en el dicho termino ni agan alguna cosa en el asta otra cosa se probea por Vuestra Corte y pide Justicia y Costas. El Licenciado Aguirre.

Miguel Ximeno, procurador del Monasterio Real de Fitero, digo que el dicho Monasterio es Dueño del Lugar, terminos y Castillo de Trujen por mercedes Reales los queles tiene y posee en propiedad y possesion y por el ynteresse que a tenido en la decima que se le haze del Cañamo por los vecinos de la dicha Villa muchos años ha que hizo u dio liçencia para que hiciesen onçe poças Junto a la Iglesia de San Balentin, termino del dicho Lugar de Trujen y comprenso de sus Limites y mojones para que en ellas se pudiesse veneficiar y Remojar el Cañamo y Linos que se hacen en aquella tierra en mui grande quantidad necesaria de los Rios de Ixea de Alama y Añamaça para solamente çurar y Veneficiar el Cañamo y Lino y a llegado agora noticia de mi parte que la dicha Villa de Fitero y algunos veçinos particulares Della tratan de agrandar y estender las dichas poças en mui grande cantidad tomando del Suelo de los dichos teminos de Trujen que es propio del Monasterio sin parte dicho concurso de las partes Contrarias mui gran pedazo de Suelo y Sitio para hazer heras y congelar alli el yelo y para que este mismo efecto tratan de tomar el agua de los dichos Rios no teniendoselas dadas el dicho Monasterio sino como se ha dicho para Veneficiar los Cañamos y Linos y regar las tierras del Monasterio que tienen en Censadas por el y no para otro ningun efecto ni caussa y por que esto es en conocido perjuicio del Drecho del Monasterio que tiene no solo en los dichos terminos sino en las aguas como Dueño dellas y tambien se les siguiran mui grandes daños de Pleitos que le podrian Resultar a esta ocassion con otras partes suplico a V. Magestad mande despachar su inhibicion penal para que la dicha Villa de Fitero ni sus Vecinos no agranden ni ensanchen mas las dichas poças ni tornen el agua susodicha para otro efecto que para Veneficiar el Cañamo y Lino como hasta aqui se ha Usado y para que se entienda si an contravenido quel Escribano que entendiere en notificar esta inhibicion de nueba obra tome por testimonio el ancho largo y alto de las dichas poças que assi es de Justicia que pido y costa. El Licenciado don Guillen.

Sobre esta Peticion se probeio inhibicion por los Señores de la Corte Mayor deste Reino y aviendose seguido el pleyto se pronunciaron las declaraciones siguientes:

\section{S. Magestad}

Estevan de Subiça, Procurador de la Villa de Fitero en la Caussa que trata contra el Monasterio de la dicha Villa o Ximeno su procurador, diçe que la Sentencia pronunciada por los Alcaldes de Vuestra Corte a sido cofirmada por los del Vuestro Consejo y tiene necesidad de traslado Della dicha Sentencia para enguarda y conservacion de su drecho suplica: a V. Magestad mande que el Secretario de la caussa le de traslado Della dicha Sentencia para enguarda de su drecho y pide Justicia. Estevan de Subiça. 
En Pamplona en Consejo, miercoles a diez y siete de Julio de mil y seyscientos y diez y nuebe, Leida esta peticion, presente Subiça procurador Suplicante, presente Ximeno procurador Contrario, el Consejo Real mando que yo el Secretario infraescrito de al Suplicante traslado, fehaciente de la Sentencia que por ella pide presente el Señor Licenciado Ceballos del Consejo, Martin de Alcoz, Secretario.

En este negocio entre partes el monasterio Real de Fitero y Ximeno su procurador ynibiente de la una y los Jurados, Vezinos y Consejo de la misma Villa y Subiça su procurador de la otra, sobre impugnación de la inhibición de esta caussa y otras cossas se declara no haver Lugar por ahora la inhibición de esta caussa pedida por el dicho monasterio y se manda que no se despache aquella y se huviere despachado no se huse Della contra los dichos Vecinos y Consejo y assi se manda y declara sin costa, esta cifrada con las cifras de los Señores Alcaldes Cruçat, Murillo y Agáiz.

En Pamplna en Corte en audiencia, Viernes a veinte y uno de Junio de mil y seyscientos y dies y nuebe, la Corte pronunzio y declaro esta declaración segun y como por ella se contiene en presentia de Ximeno y Subiça, procuradores desta causa, y la dicha Corte mando hacer auto de su pronunciación. Presente el Señor Alcalde Murillo, Martin de Erbiti, Escribano.

En este negocio entre partes el Monasterio Real de Fitero y Ximeno su procurador ynibiente de la una y los Jurados, Vezinos y Consejo de la misma Villa o Subiça su procurador de la otra sobre impugnación de la inhibición desta Caussa i sobre otras cosas.

Se confirma lo proveído por nuestra Corte a Beinte y uno de Junio próximo passado con que sea y entienda no obrando de nuebo ni ensanchando los poços y assi se declara esta cifrada con las cifras de los Señores Licenciados don Gil de Albornoz Regente Eiusa Zeballos.

En Pamplona en Consejo en audiencia, Sabado a treçe de Julio de mil y seiscientos y diez y nuebe el Consejo Real pronuncio y declaro esta declaración segun y como por ella se contiene en presentia de Ximeno y Subiça, procuradores desta causa, y de su pronunciacion mando hazer auto de ello a mi presente el Señor Licenciado Morales del Consejo, Martin de Alcoz, Secretario.

Lo que se advierte en razon de la quexa dada por el Monasterio de Fitero contra el Alcalde y Jurados y otros Vecinos de la Villa de Fitero es:

Lo primero que el monte y termino llamados San Balentin es monte comun de la ciudad de Tudela y Villas de Corella, Cintruenigo y Fitero; y como tal monte comun de la dicha ciudad y villas de tiempo ynmemorial a esta parte lo han gozado, roçado y pacido con sus ganados granados y menudos quieta y pacificamente a paz y vista cierta y tolerancia del dicho monasterio sin que jamás ubiesse avido impedimento ni contradicion alguna y como en el dicho monte como en endereçera de la Villa de Fitero a acostumbrado la mesta de la dicha Villa hazer sus añadidos y bigados para el tiempo de la paricion de sus ganados y los a guardado el dicho Monasterio y sus pastores como los demas digan los testigos la ynmemorial.

Ittem que en el dicho monte ay una hermita derrivada que dizen San Balentin y de ella a tomado nombre el dicho monte de llamarse San Balentin, pero esta inclusso y lo ha estado siempre en los montes de Cierzo y comunidad sobre dicha que en los dichos montes en diferentes partes tienen la dicha Ciudad y villas, hermitas como tambien ay otra que se dize San Pedro del Baño que esta sitia en el monte comun pero no por ello deja de ser el mesmo monte y Comunidad de todos los Comuneros. 
Itten que el Castillo que el dicho Monasterio dize y llama de Trujen esta distinto y separado del dicho monte de San Balentin y quando vino el Señor don Lope de Morales del Consejo de su Magestad en este Reino a amojonar los montes comunes, amoxono el dicho montes que llaman Castillo y afrenta con el de San Balentin y puso sus moxones como de presente estan dejando por monte y como monte comun todo lo que esta fuera de los dichos mojones, los quales se hizieron y hecharon a Vista y tolerancia del dicho Monasterio.

Itten que todos los comuneros tienen asentada costumbre de poder gozar en los montes comunes para Sembrar sus panes y tienen asentada condicion que si se desa una pieza de labrar en quatro Heneros se la puede tomar qualquiera de los comuneros y el rozar a de ser parejo con Rexa o azada porque el deshitar que es quitar piedras o ulagar no vale sino Rozando parejo con azada o Reja.

Itten que el aver Rozado en el dicho monte no a sido nobedad sino usar cada uno de su derecho y no es cosa nueba el averlo Rozado ahora, porque antes de ahora fue Rozado y se dexo por tener muchas piedras en que se rompian los arados y por esta Razon y para que se pudiese aprobechar se mandaron yr peones a sacarlas como se haze en todas las Rozas que se hazen en los dichos montes porque sin ello no se podian aprovechar.

Itten que los amojonamientos que el dicho Monasterio dize en su quexa que hizieron los conçejos de Agreda y San Pedro y la donacion que dizen de Trujen son mui fribolos y sin fundamento, pues no se tiene noticia dellos ni han estado en obserbancia, y todo lo que comprenden es [de presente] comun que a rozado y roza toda la comunidad y no obita el decir que en el dicho monte de San Balentin se mando zegar helera pues en aquello concurria diferente Razon que en esto qe no se pretende propiedad mas de usar cada uno de su drecho de hazer pieças para pan llevar ni tanpoco se abriguara que por razon en dicho monte comun de San Balentin ni otro el dicho Monasterio aya llebado como dize Reses de castillaje ques en los montes comunes naide tiene ese drecho ni en dicho monte o castillo que dizen de Trugen ay señal de castillo mas de una queba y edificio viejo.

Itten que es cosa usada y acostumbrada los pueblos yr en procesion a las hermitas, pero no por esso las Yglesias dichos eclesiasticos adquieren drecho alguno, ni tampoco se abriguara que los de Çervera ayan benido en proçesion a la dicha hermita de San Balentin, sino a otra que dezian de San Lorente que los Monjes de Fitero hacen oración quando se ba en procession a San Balentin.

Itten que el dicho Monasterio de Fitero a rozado y rozaron bien en los montes comunes como a sido en Val de la Fuente y en los Cascajos y, debaxo, el prado de los cavallos que es monte comun y en muchas partes en los montes comunes como es en los Villares de Cierzo y en los Cascaralesde Val de La Fuente y otros que estaban cimientos de edificios que avido en tiempo de moros, pero no por esto nadie adquiere propiedad ni haze mas que rozar y sembar y sacar las piedras fuera para que se pueda arar y aprovechar. 


\section{Bibliografía}

ALBEROLA ROMÁ, Armando, Los cambios climáticos. La Pequeña Edad del Hielo en España, Madrid: Cátedra, 2014.

ALFARO PÉREZ, Francisco José, La Merindad de Tudela en la Edad Moderna. Demografía y sociedad, Tudela: ADEH, Institución Fernando el Católico y los MM. II. Aytos. de Fitero, Corella y Tudela, 2006.

ALFARO PÉREZ, Francisco José, 2007. Mapa del monasterio y la villa de Fitero con todo su término e inmediaciones. En: Ricardo FERNÁNDEZ GRACIA, Fitero: el legado de un monasterio, Pamplona: Gobierno de Navarra, 2007, pp. 178-179.

ALFARO PÉREZ, Francisco José, ¡Ni abad por vecino ni fraile maitino! Análisis transversal de un conflicto antiseñorial del siglo XVII. Studia Monastica. 2019, vol. 61, pp. 175-185.

ARCINIEGA GARCÍA, Luís, Reutilización de materiales pétreos y uso de canteras en el abastecimiento de la arquitectura valenciana de época foral. En: Francesca ESPAÑOL BERTRÁN y Joan VALERO MOLINA (Coords.), Les pedreres medievals a la Corona d'Aragó, Barcelona: Institut d'Estudis Catalans, 2017, pp. 149-185.

CATALÁN MARTÍNEZ, Elena, El clero ante la crisis del siglo XVII. Conflictos y estrategias. En: Tiempos modernos. Revista electrónica. 2010, vol. 7, nº 20.

CUADRAT, José María, ALFARO PÉREZ, Fco. José, TEJEDOR, Ernesto, SERRANO-NOTIVOLI, R., BARRIENDOS, Mariano y SAZ, Miguel Ángel, La sequía de mediados del siglo XVII en el valle del Ebro. Características climáticas e impacto social del evento. En: María HERNÁNDEZ, J. OLCINA, J. F. y VERA, Paisaje, Cultura territorial y vivencia de la Geografía, Alicante: Universidad de Alicante, 2016, pp. 883-893.

FAGAN, Brian, La Pequeña Edad del Hielo. Cómo el clima afectó a la historia de Europa (1300-1850), Barcelona: Gedisa, 2008.

GARCÍA SESMA, Manuel, Investigaciones históricas sobre Fitero. Vol I, Tudela, 1986.

GARCÍA SESMA, Manuel, Investigaciones históricas sobre Fitero.Vol II, Logroño, 1989.

GARCÍA SESMA, Manuel, Poemario fiterano con notas históricas, anecdóticas y descriptivas de la villa, el monasterio y los balnearios de Fitero, Pamplona, 1989.

IDOATE, Florencio, Catálogo documental de la ciudad de Corella, Pamplona; Institución Príncipe de Viana, 1964.

MAYER, Manuel, ÁLVAREZ, Aurelio y RODÀ, Isabel, Los materiales lapídeos reaprovechados en construcciones medievales en Cataluña: la ciudad de Barcelona y su entorno. En: Artistes, artisans et production artistique au MoyenÂge, Paris, 1987, pp. 529-558.

MEDRANO MARQUÉS, Manuel y DÍAZ SANZ, María Antonia, Ocupación romana bajomedieval de Tudején (Fitero). I Congreso General de Historia de Navarra, Pamplona: Príncipe de Viana,1987, pp. 503-515. 
MEDRANO MARQUÉS, Manuel, Los visigodos en el solar de Fitero (el castillo de Tudején), Fitero, 2002.

MEDRANO MARQUÉS, Manuel, El asentamiento visigodo y musulmán de Tudején-Sanchoabarca. En:Salduie. 2004, 4, pp. 261-302.

MEDRANO MARQUÉS, Manuel, El castillo de Tudején y su entorno: últimas investigaciones. Salduie. 2018, 17, pp. 169-176.

MENÉNDEZ PIDAL DE NAVASCUÉS, Faustino, La destrucción de la memoria colecita. Un ejemplo navarro. III Congreso General de Historia de Navarra, Pamplona 20-23 de septiembre de 1994, Área III. El mundo de las ideas, Pamplona: Príncipe de Viana, 1994, pp. 1-8.

MORÁN TURINA, Miguel, 2010. La memoria de las piedras. Anticuarios, arqueólogos y coleccionistas de antigüedades en la España de los Austrias. Madrid.

OLCOZ YANGUAS, Serafín, Eleras en Fitero. Fitero (Programa), 1982, pp. 44-45.

OLCOZ YANGUAS, Serafín, Memorias del monasterio de Fitero, del padre Calatayud, Pamplona: Gobierno de Navarra, 2005.

OLCOZ YANGUAS, Serafín, El tesoro del patrimonio histórico de Fitero, Fitero, 2007.

OLCOZ YANGUAS, Serafín, Fitero cisterciense, del Monasterio a la Villa (siglos XII-XV), Fitero:Tracasa, 2008.

PARKER, Geoffrey (coord.), La crisis de la Monarquía de Felipe IV, Barcelona: Crítica, 2006.

PÉREZ MOREDA, Vicente, Las crisis de mortalidad en la España interior (siglos XVI-XIX), Madrid: Siglo XXI, 1980.

REHER SULlIVAN, David Sven, Castilla y la crisis del siglo XVII: contextos demográficos para un ajuste de larga duración. En: Enrique MARTÍNEZ RUIZ (coord.), Felipe II y las ciudades de la monarquía, Madrid, vol. 2, 2000, pp. 347-374.

SALAS AUSENS, José Antonio, Las haciendas concejiles aragonesas en los siglos XVI y XVII, de la euforia a la quiebra. En: José Antonio SALAS AUSÉNS, Armando ALBEROLA, Enrique GIMÉNEZ, Pere MOLA y José Ignacio FORTEA, Poder político e instituciones en la España moderna, Alicante, 1992, pp. 9-66.

SÁNCHEZ PARDO, José Carlos, El reuso de materiales y estructuras antiguas en las iglesias altomedievales de Galicia, casos, problemas y motivaciones. Estudos Quaternário. 2015, 12, pp. 95-110.

USUNÁRIZ GARAYOA, Jesús María, Nuevos señoríos, nuevos señores: Navarra y la venta de jurisdicciones durante la Edad Moderna. Cuadernos de Investigación Histórica. 1999, nº 17, pp. 7-36.

USUNÁRIZ GARAYOA, Jesús María, ¡Muera ese traidor, matadlo! Fitero y su régimen señorial en la Edad Moderna. En: Ignacio ARELLANO AYUSO (coord.), Modelos de vida y cultura en la Navarra de la modernidad temprana, Madrid: Instituto de Estudios Auriseculares, 2016, pp. 319-363. 
WARD-PERKINS, Bryan, Re-using the Architectural legacy of the Past, entre idéologie et pragmatisme. En: The idea and ideal of town between late Antiquity and Early Middle Age, Leiden, 1999, pp. 225-244. 